\title{
CYTO-TAXONOMY OF RHYNCHOSINAPIS AND HUTERA (CRUCIFERAE-BRASSICEAE)
}

\author{
D. J. HARBERD and E. D. MCARTHUR \\ Department of Agricultural Sciences, University of Leeds
}

Received 22.ix.71

Two species have been recognised in the genus Hutera and both have $2 n=24$ chromosomes. Rhynchosinapis is a larger genus and includes both diploid $(2 n=24)$ and tetraploid forms (see Harberd, 1972, for the full bibliography). All of the diploids in the two genera so far tested are fully crossable with each other in all combinations, and this includes $R$. cheiranthos, $R$. monensis, $R$. wrightii, $R$. pseudoerucastrum, $R$. hispida, $R$. longirostra, H. rupestris and H. leptocarpa.

Sikka (1940) observed that his tetraploid, $R$. cheiranthos, regularly formed 24 bivalents at meiosis, and with the diploids $R$. monensis and $R$. wrightii being the only other species of Rhynchosinapis known cytologically at that time, suggested that $R$. cheiranthos is the allotetraploid derived from them. However, it is now known that $R$. cheiranthos is one of the species that exists in both diploid and tetraploid races so that this interpretation seems unlikely.

Seven diploid interspecific hybrids have been grown at Leeds- $R$. cheiranthos $\times R$. monensis, and the six hybrids derived by crossing each of these species with $R$. hispida, $R$. longirostra and $H$. leptocarpa respectively. Some of the principal morphological characters of the species and hybrids are listed in table 1. Examination of the pollen in acetocarmine indicated that without exception the hybrids produced uniformly plump stainable grains indistinguishable from those of the parent species. It seemed unlikely, therefore, that there could be any major cytological disturbance at meiosis, and this was found to be so-apart from a few unpaired chromosomes in about 3 per cent. of the P.M.C. there was complete bivalent formation (table 2). Furthermore, there is no difference between the hybrids in this pairing behaviour, which is, in our experience, exactly like that of the parental species. Thus no evidence was found to suggest that there is any cytological differentiation between the diploid species included in this study-it may exist elsewhere in the genera of course but this seems unlikely since most of the taxonomic range had been included.

Our study of the tetraploids confirms Sikka's observation that they are essentially bivalent forming. Of 173 cells examined only a single doubtful quadrivalent was observed, all the other cells having 24 bivalents except that in 10 of the cells 2 or 4 of the chromosomes remained unpaired. Nevertheless we believe the tetraploid to be autotetraploid, our evidence being threefold:

1. The close morphological resemblance between the diploids as a group and the tetraploids, and the apparent absence of a second genome among the diploids.

2. The fact that triploid hybrids, table 3 , behave in a typical autotriploid manner at meiosis.

3. One aberrant tetraploid with $2 n=50$ forms occasional quadrivalents and trivalents, table 4. 
NOTES AND COMMENTS
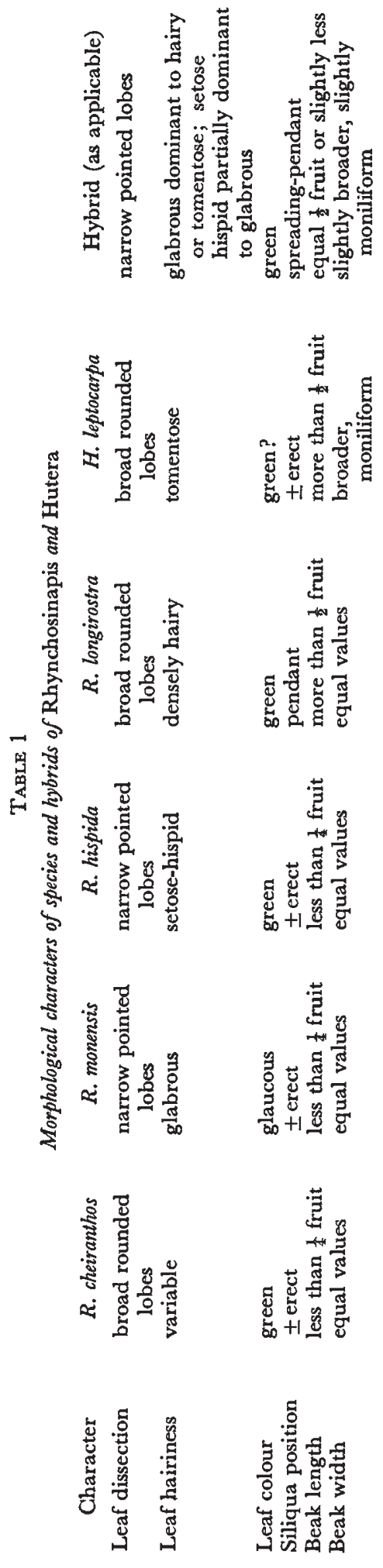


\section{TABLE 2}

Meiotic metaphase pairing in some diploid Rhynchosinapis and Hutera hybrids

Chromosome pairing

\section{Hybrid}

$R$. cheiranthos $\times R$. monensis

$R$. cheiranthos $\times R$. hispida

$R$. cheiranthos $\times R$. longirostra

$R$. cheiranthos $\times H$. leptocarpa

H. leptocarpa $\times R$. monensis
$R$. longirostra $\times R$. monensis

$\begin{array}{lrrrr}\text { Bivalents: } & \overbrace{}^{\text {Chromosome pairing }} \\ \text { Univalents: } & - & 11 & 10 & 9 \\ & 69 & 2 & 4 & 6 \\ & 65 & 2 & - & - \\ & 32 & - & - & - \\ 53 & 1 & - & - \\ & 148 & 3 & 1 & 1 \\ 59 & 1 & 2 & - \\ & 426 & 9 & 4 & 1\end{array}$

TABLE 3

Meiotic pairing in triploid Rhynchosinapis

R. pseudoerucastrum (tetraploid) $\times$

\begin{tabular}{ccc}
\multicolumn{3}{c}{ Configurations } \\
$\overbrace{\text { Trivalents }}^{\text {Bivalents }}$ & Univalents \\
8 & 4 & 4 \\
7 & 5 & 5 \\
6 & 6 & 6 \\
5 & 7 & 7 \\
4 & 8 & 8 \\
3 & 9 & 9 \\
2 & 10 & 10 \\
1 & 11 & 11 \\
0 & 12 & 12
\end{tabular}

TABLE 4

Meiotic pairing in an aneuploid tetraploid Rhynchosinapis

Configurations

$\begin{array}{ccccc}\text { Quadrivalents } & \text { Trivalents } & \text { Bivalents } & \text { Univalents } & \\ 2 & - & 19 & 4 & 1 \\ 2 & 1 & 19 & 1 & 2 \\ - & 2 & 21 & 2 & 2 \\ 1 & - & 23 & - & 3 \\ - & 1 & 23 & 1 & 8 \\ - & - & 25 & - & 23 \\ - & - & 24 & 2 & 5 \\ - & - & 23 & 4 & 1\end{array}$

It appears that in this material chromosome pairing is limited to bivalent formation in the autotetraploids, but that this control has been broken down in the triploids, and also partially so in the aneuploid. A somewhat similar case has been reported by Mulligan (1967) in Physaria vitulifera (Cruciferae). The haploid chromosome number is four; diploids form four bivalents, tetraploids, eight bivalents, but triploids form trivalents, up to four in number. 


\section{REFERENGES}

HARBERD, D. J. 1971. A contribution to the cytotaxonomy of Brassica (Cruciferae) and its allies. Bot. F. Linn. Soc., 65, 1-23.

mulligan, G. A. 1967. Diploid and autotetraploid Physaria vitulifera (Cruciferae). Can. $\mathcal{F}$. Bot., 45, 183-188.

sikka, s. M. 1940. Cytogenics of Brassica hybrids and species. F. Genet., 40, 441-509. 